\title{
Comorbid Psychiatric Symptoms in Childhood Stutterers: An Egyptian Sample
}

\author{
Original \\ Article \\ Reham Ahmed Fahiem', Amal Mohamed Hamad ${ }^{2}$ Dina Y. Elalfy \\ Department of ${ }^{1,3}$ Medical Studies for Children, ${ }^{2}$ Child Psychological Studies, Faculty of \\ Postgraduate Childhood Studies, Ain Shams University, Egypt.
}

\begin{abstract}
Introduction: Stuttering is a fluency disorder in which an individual can produce speech effortlessly and automatically and it is seriously compromised. Although the spontaneous recovery rate is high in children, stuttering will become an intractable problem for some of them. In Egypt, it occurs at the Prevalence of 0.29- 0.55\%. Stuttering is one of the speech disorders which is characterized by developmental histories often marked by bullying, poor peer relationships, and many negative social interactions. Therefore, it is clear that stuttering carries a significant risk of comorbid psychiatric symptoms; these psychiatric symptoms appear in children and persist into adulthood. The theories behind stuttering and mental health disorders are complex.

Aim: The current study aimed to determine comorbid psychiatric symptoms in stutterers.

Patients and Methods: A cross-sectional study was done on forty- seven stutterers. They were classified into three groups: children group: their age ranged 6 - 9.7 years $(7.4 \pm 1.3)$, preadolescents group: their age ranged $10-11.8$ years $(10.6 \pm 0.6)$ and adolescents group: their age ranged 13.1- 17.2 years $(15.1 \pm 1.5)$, who were diagnosed with stuttering. Child Behavior Checklist (CBCL) and Arabic Stuttering Severity Instrument (A- SSI) were applied to all of them.

Results: Comorbid psychiatric symptoms were associated with stuttering. It was found that psychiatric co-morbidities aggravated the stuttering severity. These psychiatric symptoms appeared in children, preadolescents and became more prominent in adolescents.

Conclusion: The current study demonstrated stuttering as a heterogeneous group of disorders. Cognitive behavior therapy (CBT) is mandatory for stutterers in addition to the ordinary management program, which includes speech assessment and intervention. On the other hand, CBT should be used as a prophylactic therapy in stutterers without comorbid psychiatric symptoms.
\end{abstract}

Key Words: CBCL, CBT, co-morbidity, stuttering.

Received: 3 May 2021, Accepted: 16 July 2021

Corresponding Author: Reham Ahmed Fahiem, MD, Department of Medical Studies for Children, Faculty of Postgraduate Childhood Studies, Ain Shams University, Cairo, Egypt, Tel.: 01111117254, E-mail: rahoma2006@hotmail.com

ISSN: 2090-0740, 2022

\section{INTRODUCTION}

Stuttering is a speech disorder that causes an inability to express their wants and ideas ${ }^{[1]}$. Stuttering disorder is a heterogeneous disorder associated with secondary behaviors that the stutterers use to escape speech situations $^{[2]}$. The stuttering prevalence rate was $1 \%$, and its incidence rate was $4-5 \%{ }^{[3]}$. The prevalence of stuttering was $0.72 \%$ across the whole population, with the highest and lowest prevalence rates having been in younger children (1.4-1.44) and adolescents $(0.53)^{[4]}$. Stuttering can be presented by sounds or syllables disruption that might be associated with some auxiliary practices, including eye $\&$ jaw twitching ${ }^{[5,6]}$. Speech disruptions are related to physiological, behavioral, and emotional reactions ${ }^{[7]}$.

Based on Raghavendra et al., the stutterer's life was affected not by the stuttering itself but due to their social limitations ${ }^{[8]}$. Several endogenous and exogenous factors should be minded. Stutterers had impaired psychological health outcomes compared to typically fluent speakers ${ }^{[9]}$.

The mental variables created stuttering, for example, nervousness, as opposed to a physiological cause. Even though it was trusted that suspicion brought on stuttering, there is no proof supporting this ${ }^{[8]}$. Stutterers are emotionally unstable and unable to communicate freely in their life ${ }^{[10]}$, there are multiple emotional reactions like nervous, insecure, tense, fearful, shyness, escape behavior, hesitant, and depressed ${ }^{[11]}$.

It was stated that the negative perspective of stutterers might be aggravated with age when the child becomes more anxious about people's disapproval ${ }^{[5,6]}$. Stutters had poor adaptive functions regarding internalizing, externalizing behavior, general anxiety, and depression ${ }^{[13]}$. Stutterers usually react to their disfluency by denial, guilt, shame, anxiety, depression, and anger. Their parents reported that 
they typically have behavioral problems with them and with school peers ${ }^{[14]}$. Anxiety in stutterers may increase over time till it became more evident in adolescents. ${ }^{[15]}$

Stuttering's psychosocial aspect is one of the significant components of this disorder that needs special attention in treatment. Stuttering is accompanied by destructive feelings of frustration, anger, guilt, and humiliation ${ }^{[16]}$. The degree of the impact of stuttering on a person's life differs among individuals ${ }^{[17]}$. Previous studies discussed anxiety and its social effect in detail, as were the most common mental disorders in adolescents' stuttering population.

According to Freud's theory of psychoanalysis, stuttering is viewed as merely an overt symptom of something else unconscious, deep- seated neurotic disorders ${ }^{[18]}$. The current work measured the effect of eight psychological, mental symptoms (anxiety, withdrawn, social problems, thoughts problems, attention problems, aggressive behavior, rule-breaking habits \& somatic complaints) among childhood stutterers. The authors summarized how these psychological health outcomes are considered features related to secondary manifestations of stuttering in the childhood stage.

\section{OBJECTIVES:}

The current study aimed to determine comorbid psychiatric symptoms in children, preadolescent and adolescent stutterers and highlight the correlations of different factors in stuttering patients.

\section{PATIENTS AND METHODS:}

\section{1. study design}

A cross-sectional study was done on forty- seven patients. The stutterers were chosen according to the inclusion and exclusion criteria. All parents agreed to undergo the assessment and had informal consent. The study was approved by the Ethics Committee of the Faculty of Postgraduate Childhood Studies (FPGCS), Ain Shams University, and protocol no. RHDIRB2020110401.

This study included forty-seven Egyptian stuttering patients presented in three groups: children group: their age ranged 6 - 9.7 years, preadolescents group: their age ranged 10 - 11.8 years and adolescents group: their age ranged 13.1- 17.2 years, complaining of inability to talk fluently as expected for their age. The study included thirty-six males and eleven females. The authors classified the participant into three groups according to age: Group 1: (children's stutterers); 16 patients. Group 2: (preadolescent stutterers); 17 patients. Group 3: (adolescent stutterers); 14 patients.

\subsection{Assessment:}

\subsubsection{History}

\section{A detailed history was taken, including:}

A) Personal and family to exclude the hereditary factor of stuttering.

B) Past History to exclude any psychiatric disorders.

\subsubsection{Inclusion criteria}

1- Diagnosis of stuttering.

2- $\quad$ They diagnosed at a minimum of 12 months ago of dysfluency.

3- The children were all selected to have an average IQ and no history of previous speech therapy.

4- The native speaker is Arabic, and the age is between 6 and 18 years old.

\subsubsection{Exclusion criteria}

Any psychological illness that interferes with stuttering

Any history of language or speech disorders.

\subsection{Procedures:}

1- Auditory perceptual assessment (APA) was done for both automatic speech and spontaneous speech to detect stuttering's core behavior. The audiovisual record was performed, composed of at least 100 words, and reading passages, with a Sony digital camcorder and a tripod.

2- Assessment of the stuttering severity was done by Arabic versions of the stuttering severity instrument (A-SSI) ${ }^{[19]}$, which was adapted from the original version of the Stuttering Severity Instrument $(\mathrm{SSI})^{[20,21]}$. A stuttering severity scored as following: (0-20) is very mild, (21-24) is mild, (25-31) is moderate, (32-35) is severe, and (36-45) is very severe.

3- The child behavior checklist (CBCL) is a reliable and valid tool. The Arabic version of the $\mathrm{CBCL}$ (6-18y) questionnaire was answered by the parents and scored manually by the pediatrician to detect different psychological problems. This Arabic version of CBCL was developed by ${ }^{[22]}$ and rated through the original English version of CBCL by ${ }^{[23]}$. The Internalizing Domain measures emotional problems: Anxious/Depressed, Withdrawn/ Depressed, and Somatic Complaints.The Externalizing Domain measures behavioral issues: The Rule-Breaking Behavior and Aggressive Behavior syndrome scales.Three 
other Thought Problems, social problems, and attention problems.

\subsection{Statistical analysis:}

The tabulated data presented, and analysis was done by (SPSS 15.0 for windows; SPSS Inc., Chicago, IL, 2001). The authors used One-Sample Kolmogrovo- Smirnov to evaluate normal distribution parameters. Pearson Correlations were used to assess the strength of association between two quantitative variables. While Qualitative data was evaluated using the Chi-Square test and Fisher's exact Chi-Square test.

\section{RESULTS:}

This study was conducted on forty-seven patients with stuttering; their age range was (6-18) years. There were classified into three main groups Group1: (children stutterers); 16patients (15 boys, one girl), with a mean age (7.4 \pm 1.3 years). Group2: (preadolescent stutterers); 17 patients (13 males, four females), with a mean age (10.8 \pm 0.6 years). Group3: (adolescent stutterers); 14 patients ( 8 males, six females), with mean age (15.1 \pm 1.5$)$. Demographic characteristics of the subjects (Table 1).

Correlation analyses were done, there was an inverse correlation between age and percent of cases of stuttering with (normal) CBCL $(\mathrm{r}=-0.61, p=<0.001)$. A significant statistically (direct relation) correlation has been demonstrated between ages and A-SSI, percent of cases of borderline CBCL \& percent of clinical cases of CBCL (Table 2).

This (Figure 1) revealed that (1) anxious/ depressed symptoms were much higher in preadolescents than in other age groups. (2) Withdrawn/ depressed symptoms were much higher in occurrence in adolescents than in different age groups. (3) Somatic complaint symptoms were much higher in adolescents than in other age groups (4) Rule-breaking behavior symptoms were much higher in preadolescents than in different age groups, with a marked decrease in adolescents. (5) Aggressive symptoms were much higher in occurrence in adolescents than in other age groups. (6). Social problem symptoms were much higher in occurrence in preadolescents than in different age groups. (7) Thought problems were a much higher occurrence in preadolescents, with a marked decrease in adolescents. (8) Attention problems symptoms were much more significant in occurrence in preadolescents than in other age groups.

Figure 2, Showed the effect of age on the mean of stuttering severity and explained that the stuttering severity was increased directly with age.

There were statistically highly significant differences between the degree of stuttering severity and different age (Table3).

According to ages (children, preadolescents \& adolescents), there was a highly significant correlation in (anxious/ depressed, withdrawal/ depressed, somatic complaints, thought problems \& social problems, rulebreaking behavior), and significant in (aggressive behavior) \& non-significant with attention problems (Table 4).

Intra analysis and Correlation between SSI and CBCL items in each age group showed that there were highly significant direct correlations between SSI and anxiety, withdrawal, social problems, thoughts problems, and attention problems among the children group. There were significant direct correlations between SSI and rule-breaking habits, aggressive behavior and no correlation between A-SSI and somatic complaints. Among preadolescent group: there were no correlations between SSI and anxiety, withdrawal, social problems, thoughts problems, and attention problems; there were direct correlations between SSI and rule-breaking habits, aggressive behavior. There were no correlations among adolescents' stutterers (Table 5).

Among all age groups, there were highly significant correlations between A-SSI severity and anxiety, withdrawal. There were significant direct correlations between A-SSI and social problems, thoughts problems, aggressive behavior, and no correlation between A-SSI among children who stutter. There weren't correlations between SSI and attention problems, rule-breaking habits, and somatic complaints (Table 6).

Table 1: Demographic characteristics of the subjects

\begin{tabular}{lccc} 
& Children $(\mathrm{n}=16)$ & Preadolescent $(\mathrm{n}=17)$ & Adolescent $(\mathrm{n}=14)$ \\
\cline { 2 - 4 } Age (years), mean \pm SD & $7.4 \pm 1.3$ years & $10.8 \pm 0.6$ years & $15.1 \pm 1.5$ year \\
Sex $(\mathrm{n})$ & 15 & 13 & 8 \\
Male $(\mathrm{n}=36)$ & 1 & 4 & 6 \\
Female $(\mathrm{n}=11)$ & &
\end{tabular}


Table 2: Correlation between all age groups with A- SSI and percentage of cases as regards (normal, borderline, and clinical)

\begin{tabular}{|c|c|c|c|c|c|}
\hline & & ASSI & Normal\% & Borderline $\%$ & Clinical $\%$ \\
\hline \multirow{3}{*}{ Age } & $r$ & 0.71 & -0.61 & 0.36 & 0.56 \\
\hline & Pvalue & $<0.001^{* *}$ & $<0.001^{* *}$ & $0.014^{*}$ & $<0.001^{* *}$ \\
\hline & Sig. & HS & HS & $\mathrm{S}$ & HS \\
\hline
\end{tabular}

Pearson correlation, $* *=\mathrm{HS}, *=\mathrm{S}$

Table 3: Distribution and correlation of stuttering severity degree across all age groups

\begin{tabular}{llllll}
\hline Degree of stuttering & $\begin{array}{l}\text { Children } \\
(\mathrm{n}=16)\end{array}$ & $\begin{array}{l}\text { Preadolescent } \\
(\mathrm{n}=17)\end{array}$ & $\begin{array}{l}\text { Adolescents } \\
(\mathrm{n}=14)\end{array}$ & $\mathrm{X}^{2}$ & P-Value \\
\hline Mild & $5(31.3 \%)$ & 0 & 0 & & $<0.001$ \\
Moderate & $10(62.5 \%)$ & $8(47.1 \%)$ & $2(14.3 \%)$ & 24.23 & HS \\
Severe & $1(6.3 \%)$ & $2(11.8 \%)$ & $4(28.6 \%)$ & $8(57.1 \%)$ & \\
Very severe & 0 & $7(41.2 \%)$ & & \\
\hline
\end{tabular}

Fisher's Exact Test Chi-Square Test

Table 4: Distribution and correlations of psychiatric symptoms among three age groups

\begin{tabular}{|c|c|c|c|c|c|c|}
\hline Anxious & $\begin{array}{l}\text { Children } \\
(n=16)\end{array}$ & $\begin{array}{l}\text { Preadolescents } \\
(n=17)\end{array}$ & $\begin{array}{l}\text { Adolescents } \\
(\mathrm{n}=14)\end{array}$ & $\mathrm{X}^{2}$ & P-Value & Sig. \\
\hline normal & $13(81.3 \%)$ & $1(5.9 \%)$ & 0 & & & \\
\hline Borderline & $1(6.3 \%)$ & $1(5.9 \%)$ & $2(14.3 \%)$ & 31.44 & $<0.001$ & HS \\
\hline Clinical & $2(12.5 \%)$ & $15(88.2 \%)$ & $12(85.7 \%)$ & & & \\
\hline \multicolumn{7}{|l|}{ Withdrawn } \\
\hline normal & $8(50.0 \%)$ & $1(5.9 \%)$ & 0 & & & \\
\hline Borderline & $3(18.8 \%)$ & $5(29.4 \%)$ & $1(7.1 \%)$ & 16.64 & 0.001 & HS \\
\hline Clinical & $5(31.3 \%)$ & $11(64.7 \%)$ & $13(92.9 \%)$ & & & \\
\hline \multicolumn{7}{|c|}{ Somatic complaints } \\
\hline normal & $16(100.0 \%)$ & $12(70.6 \%)$ & $5(35.7 \%)$ & & & \\
\hline Borderline & 0 & $1(5.9 \%)$ & $1(7.1 \%)$ & 15.47 & 0.001 & HS \\
\hline Clinical & 0 & $4(23.5 \%)$ & $8(57.1 \%)$ & & & \\
\hline \multicolumn{7}{|c|}{ Social problems } \\
\hline normal & $11(68.8 \%)$ & $3(17.6 \%)$ & $4(28.6 \%)$ & & & \\
\hline Borderline & $4(25.0 \%)$ & $4(23.5 \%)$ & $2(14.3 \%)$ & 14.34 & 0.005 & HS \\
\hline Clinical & $1(6.3 \%)$ & $10(58.8 \%)$ & $8(57.1 \%)$ & & & \\
\hline \multicolumn{7}{|c|}{ Thought problems } \\
\hline normal & $16(100.0 \%)$ & $8(47.1 \%)$ & $5(35.7 \%)$ & & & \\
\hline Borderline & 0 & $3(17.6 \%)$ & $8(57.1 \%)$ & 21.92 & $<0.001$ & HS \\
\hline Clinical & 0 & $6(35.3 \%)$ & $1(7.1 \%)$ & & & \\
\hline \multicolumn{7}{|c|}{ Attention problems } \\
\hline normal & $14(87.5 \%)$ & $9(52.9 \%)$ & $7(50.0 \%)$ & & & \\
\hline Borderline & $1(6.3 \%)$ & $3(17.6 \%)$ & $3(21.4 \%)$ & 6.09 & 0.185 & NS \\
\hline Clinical & $1(6.3 \%)$ & $5(29.4 \%)$ & $4(28.6 \%)$ & & & \\
\hline \multicolumn{7}{|c|}{ Rule-breaking habits } \\
\hline normal & $15(93.8 \%)$ & $8(47.1 \%)$ & $11(78.6 \%)$ & & & \\
\hline Borderline & $1(6.3 \%)$ & $2(11.8 \%)$ & $2(14.3 \%)$ & 11.29 & 0.008 & HS \\
\hline Clinical & 0 & $7(41.2 \%)$ & $1(7.1 \%)$ & & & \\
\hline \multicolumn{7}{|c|}{ Aggressive behavior } \\
\hline normal & $14(87.5 \%)$ & $8(47.1 \%)$ & $6(42.9 \%)$ & & & \\
\hline Borderline & $1(6.3 \%)$ & $2(11.8 \%)$ & $2(14.3 \%)$ & 8.66 & 0.047 & $\mathrm{~S}$ \\
\hline Clinical & $1(6.3 \%)$ & $7(41.2 \%)$ & $6(42.9 \%)$ & & & \\
\hline
\end{tabular}

Fisher's Exact Test Chi-Square Test 
Table 5: Intra analysis and Correlation between SSI and CBCL in each age group

\begin{tabular}{|c|c|c|c|c|c|c|c|c|c|}
\hline SSI & & anxious & withdrawn & $\begin{array}{l}\text { somatic } \\
\text { complaints }\end{array}$ & $\begin{array}{l}\text { social } \\
\text { problems }\end{array}$ & $\begin{array}{l}\text { thoughts } \\
\text { problems }\end{array}$ & $\begin{array}{l}\text { attention } \\
\text { problems }\end{array}$ & $\begin{array}{l}\text { rule- } \\
\text { breaking } \\
\text { habits }\end{array}$ & $\begin{array}{l}\text { aggressive } \\
\text { behavior }\end{array}$ \\
\hline$r$ & & 0.80 & 0.77 & 0.46 & 0.76 & 0.74 & 0.73 & 0.57 & 0.62 \\
\hline \multirow{2}{*}{ Children } & $P$ Value & $<0.001^{* *}$ & $0.001^{* *}$ & 0.071 & $0.001^{* *}$ & $0.001^{* *}$ & $0.001^{* *}$ & & $0.011^{*}$ \\
\hline & Sig. & HS & HS & NS & HS & HS & HS & $\mathrm{S}$ & $\mathrm{S}$ \\
\hline \multirow{3}{*}{$\begin{array}{l}\text { Pre- } \\
\text { adolescents }\end{array}$} & $r$ & 0.23 & 0.10 & -0.13 & 0.24 & 0.37 & -0.05 & 0.50 & 0.49 \\
\hline & $P$ Value & 0.367 & 0.701 & 0.632 & 0.349 & 0.143 & 0.849 & $0.040^{*}$ & $0.044^{*}$ \\
\hline & Sig. & NS & NS & NS & NS & NS & NS & $\mathrm{S}$ & $\mathrm{S}$ \\
\hline \multirow{3}{*}{ adolescents } & $r$ & 0.40 & 0.11 & -0.09 & -0.10 & 0.14 & -0.05 & -0.14 & 0.13 \\
\hline & $P$ Value & 0.151 & 0.702 & 0.760 & 0.729 & 0.638 & 0.858 & 0.624 & 0.669 \\
\hline & Sig. & NS & NS & NS & NS & NS & NS & NS & NS \\
\hline
\end{tabular}

Pearson correlation, $* *=\mathrm{HS}, *=\mathrm{S}$

Table 6: The inter Comparison and correlation between ASSI severity among all ages and CBCL items

\begin{tabular}{|c|c|c|c|c|c|c|c|c|}
\hline & & $\begin{array}{l}\text { Mild } \\
(\mathrm{n}=5)\end{array}$ & $\begin{array}{l}\text { Moderate } \\
(\mathrm{n}=20)\end{array}$ & $\begin{array}{c}\text { severe } \\
(n=7)\end{array}$ & $\begin{array}{l}\text { Very Severe } \\
(\mathrm{n}=15)\end{array}$ & $\mathrm{X}^{2}$ & P-Value & Sig. \\
\hline \multirow{3}{*}{ Anxious } & normal & $5(100.0 \%)$ & $9(45.0 \%)$ & 0 & 0 & \multirow{3}{*}{23.60} & \multirow{3}{*}{$<0.001$} & \multirow{3}{*}{$\mathrm{HS}$} \\
\hline & borderline & 0 & $2(10.0 \%)$ & $1(14.3 \%)$ & $1(6.7 \%)$ & & & \\
\hline & clinical & 0 & $9(45.0 \%)$ & $6(85.7 \%)$ & $14(93.3 \%)$ & & & \\
\hline \multirow{3}{*}{ Withdrawn } & normal & $5(100.0 \%)$ & $4(20.0 \%)$ & 0 & 0 & \multirow{3}{*}{21.23} & \multirow{3}{*}{$<0.001$} & \multirow{3}{*}{$\mathrm{HS}$} \\
\hline & borderline & 0 & $5(25.0 \%)$ & 0 & $4(26.7 \%)$ & & & \\
\hline & clinical & 0 & $11(55.0 \%)$ & $7(100.0 \%)$ & 11 & & & \\
\hline \multirow{3}{*}{$\begin{array}{c}\text { Somatic } \\
\text { complaints }\end{array}$} & normal & $5(100.0 \%)$ & $15(75.0 \%)$ & $4(57.1 \%)$ & $9(60.0 \%)$ & \multirow{3}{*}{4.67} & \multirow{3}{*}{0.632} & \multirow{3}{*}{$\mathrm{NS}$} \\
\hline & borderline & 0 & $1(5.0 \%)$ & 0 & $1(6.7 \%)$ & & & \\
\hline & clinical & 0 & $4(20.0 \%)$ & $3(42.9 \%)$ & $5(33.3 \%)$ & & & \\
\hline \multirow{3}{*}{$\begin{array}{c}\text { Social } \\
\text { problem }\end{array}$} & normal & $5(100.0 \%)$ & $9(45.0 \%)$ & $2(28.6 \%)$ & $2(13.3 \%)$ & \multirow{3}{*}{13.34} & \multirow{3}{*}{0.020} & \multirow{3}{*}{$\mathrm{S}$} \\
\hline & borderline & 0 & $4(20.0 \%)$ & $3(42.9 \%)$ & $3(20.0 \%)$ & & & \\
\hline & clinical & 0 & $7(35.0 \%)$ & $2(28.6 \%)$ & $10(66.7 \%)$ & & & \\
\hline \multirow{3}{*}{$\begin{array}{l}\text { Thoughts } \\
\text { problem }\end{array}$} & normal & $5(100.0 \%)$ & $15(75.0 \%)$ & $4(57.1 \%)$ & $5(33.3 \%)$ & \multirow{3}{*}{12.37} & \multirow{3}{*}{0.026} & \multirow{3}{*}{$\mathrm{S}$} \\
\hline & borderline & 0 & $4(20.0 \%)$ & $3(42.9 \%)$ & $4(26.7 \%)$ & & & \\
\hline & clinical & 0 & $1(5.0 \%)$ & 0 & $6(40.0 \%)$ & & & \\
\hline \multirow{3}{*}{$\begin{array}{l}\text { Attention } \\
\text { problem }\end{array}$} & normal & $5(100.0 \%)$ & $14(70.0 \%)$ & $4(57.1 \%)$ & $7(46.7 \%)$ & \multirow{3}{*}{4.87} & \multirow{3}{*}{0.559} & \multirow{3}{*}{$\mathrm{NS}$} \\
\hline & borderline & 0 & $3(15.0 \%)$ & $1(14.3 \%)$ & $3(20.0 \%)$ & & & \\
\hline & clinical & 0 & $3(15.0 \%)$ & $2(28.6 \%)$ & $5(33.3 \%)$ & & & \\
\hline \multirow{3}{*}{$\begin{array}{c}\text { Rule } \\
\text { breaking } \\
\text { behaviour }\end{array}$} & normal & $5(100.0 \%)$ & $16(80.0 \%)$ & $6(85.7 \%)$ & $7(46.7 \%)$ & \multirow{3}{*}{6.78} & \multirow{3}{*}{0.259} & \multirow{3}{*}{ NS } \\
\hline & borderline & 0 & $2(10.0 \%)$ & 0 & $3(20.0 \%)$ & & & \\
\hline & clinical & 0 & $2(10.0 \%)$ & $1(14.3 \%)$ & $5(33.3 \%)$ & & & \\
\hline \multirow{3}{*}{$\begin{array}{c}\text { Aggressive } \\
\text { behaviour }\end{array}$} & normal & $5(100.0 \%)$ & $14(73.7 \%)$ & $4(57.1 \%)$ & $4(26.7 \%)$ & \multirow{3}{*}{11.78} & \multirow{3}{*}{0.032} & \multirow{3}{*}{$\mathrm{S}$} \\
\hline & borderline & 0 & $2(10.5 \%)$ & 0 & $3(20.0 \%)$ & & & \\
\hline & clinical & 0 & $3(15.8 \%)$ & $3(42.9 \%)$ & $8(53.3 \%)$ & & & \\
\hline
\end{tabular}

Among all age groups, there were highly significant correlations between A-SSI severity and anxiety, withdrawal. There were direct significance correlations between A-SSI and social problems, thoughts problems, and aggressive behavior, and no correlation between A-SSI among children who stutter. There weren't correlations between SSI and attention problems, rule-breaking habits, and somatic complaint 
Fig. 1: Distribution of the percentage of occurrence of psychiatric symptoms among stuttering participants according to their age groups.

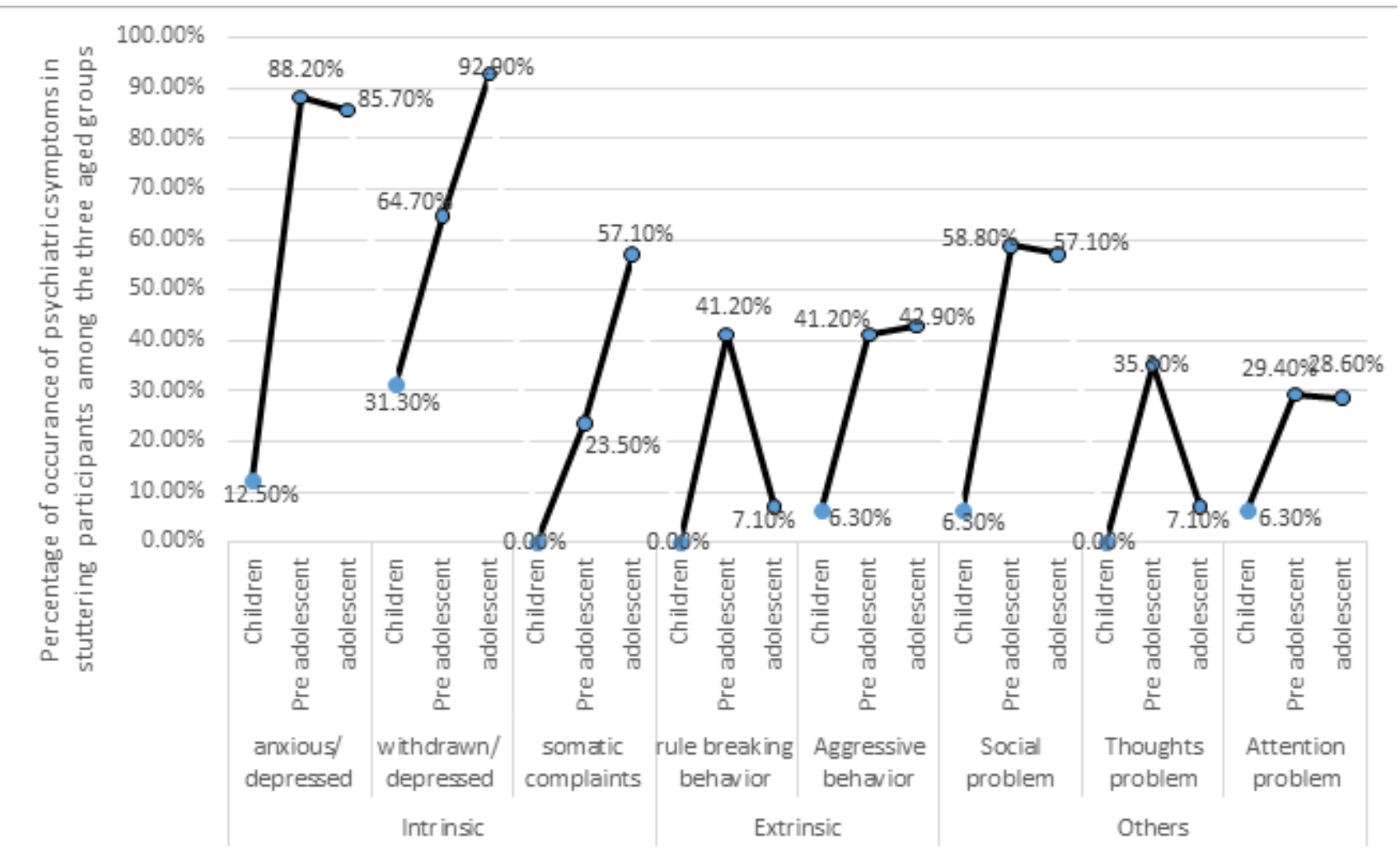

This figure (1) revealed that (1) anxious/depressed symptoms were much higher in preadolescents than in other age groups. (2) Withdrawn/ depressed symptoms were much higher in occurrence in adolescents than in different age groups. (3) Somatic complaint symptoms were much higher in adolescents than in other age groups (4) Rule-breaking behavior symptoms were much higher in preadolescents than in different age groups, with a marked decrease in adolescents. (5) Aggressive symptoms were much higher in occurrence in adolescents than in other age groups. (6). Social problem symptoms were much higher in occurrence in preadolescents than in different age groups. (7) Thought problems were a much higher occurrence in preadolescents, with a marked decrease in adolescents. (8) Attention problems symptoms were much more significant in occurrence in preadolescents than in other age groups.

Showed the distribution of the percentage of occurrence of psychiatric symptoms among stuttering participants according to their age groups

Fig. 2: Distribution of the mean of stuttering severity among the three age groups

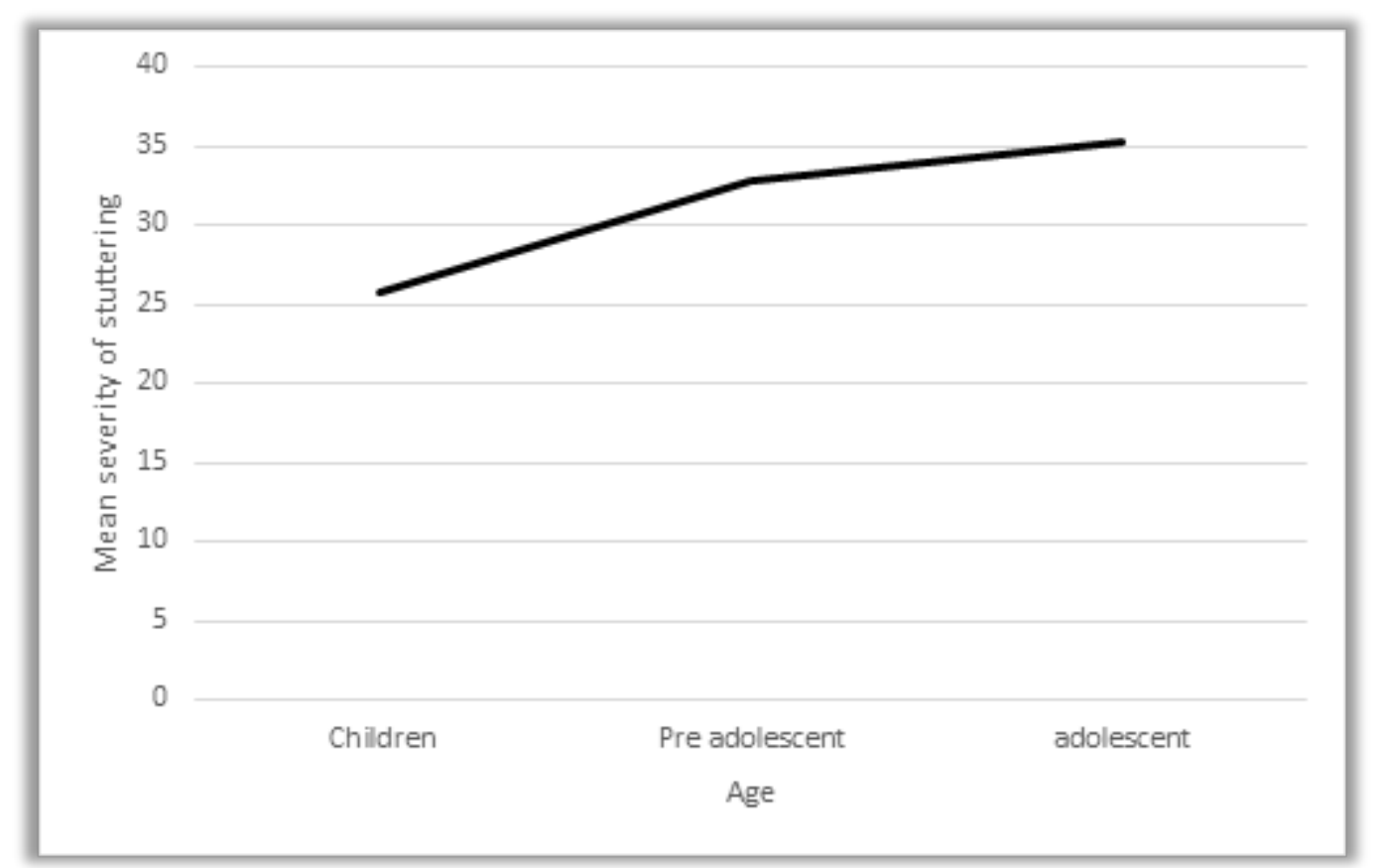

Showed the effect of age on the mean of stuttering severity and revealed that the stuttering severity was increased directly with age. 


\section{DISCUSSION}

The psychological health trajectory is unclear. The aim was to assess and determine comorbid psychiatric symptoms in childhood stutterers and highlight the correlations of different factors in stuttering patients.

Stuttering and psychiatric symptoms have different identities, but they may have some consequent relation. There is a hypothesis that stuttering and psychiatric disorders are various specific disorders; however, they may meet at an undefined point. A standard association that stuttering patients being anxious from some particularized situations may vary from one stutterer to another and increase their nonfluency condition. This anxiety feeling is induced by the stuttering situation or related to speaking situations ${ }^{[24]}$. $^{[7,25]}$ discussed the behavioral and social aspects of stutterers. Other studies provide comparative results with stutterers ${ }^{[14]}$. However, this study is the first one to target children, preadolescents, and adolescents. Preadolescence is almost a transitional zone between children and adolescents. Individuals face much ignorance, as it is much filled with emotion liability, responsibility, and hormonal disturbance.

The male- to- female ratio is matched with ${ }^{[4]}$; present, the male- to- female ratio ranged from 2.3:1 in younger children to $4: 1$ in adolescents, with the ratio of 2.3:1 registered across all ages. Interestingly, the incidence and recovery from stuttering are related to gender. At the age of onset, more boys stutter than girls, about a two- to- one-sex ratio.

There was a highly significant statistical negative correlation between age and cases of stuttering, but (normal) CBCL ( $\mathrm{r}=-0.61, p=<0.001)$ meaning that the increase of age aggravated psychiatric symptoms, and the percent of cases with free of psychiatric symptoms decrease. Despite this, there was a direct correlation. Psychiatric co-morbidity with stuttering is associated with a more severe and more prolonged illness duration ${ }^{[2]}$. Adverse reactions and thoughts against stuttering start when a child notices his speech differences ${ }^{[26-27]}$ and continues throughout life $^{[28]}$. Participants with stuttering demonstrate avoidance behaviour's, anxiety, aggression, with conflicts existing in most of them due to the listeners' adverse reactions and negative attitude to their speeches ${ }^{[29-30]}$. These negative experiences lead to feelings of embarrassment, shame, and lack of academic achievement. The probability of having psychological, behavioural, and emotional disorders is higher among them ${ }^{[31-32]}$.

Concerning behavior, the intra- group analysis was related to comorbid psychiatric symptom in the present study shown in (Figure 1) was discussed as classification of CBCL (Internalizing problems, externalizing problems and others) as follow:

Internalizing problems: Regarding anxiety/ withdrawal, its clinical range presents $91.8 \%$ in adolescents, $64.7 \%$ in preadolescents, and $31.3 \%$ in children. Stutterers' behavior was in agreement with previous studies ${ }^{[33,11,12,34]}$. Despite stutterers being afraid of the listener's negative reaction, they need more effort to be perceived more expectedly and cause an inability to communicate effectively in daily life ${ }^{[11]}$.

In anxious/depressive symptoms (children $=12.5 \%$, preadolescents $=88.2 \%$, adolescents $=85.7 \%$ ), and Abdelhamid et al., study showed that $68.6 \%$ of stutterers have an anxiety disorder as proved by a subjective anxiety test $\mathrm{t}^{[35]}$. In a Portuguese study, anxiety/depression was $28.1 \%{ }^{[14]}$. In contrary to the current study, a study found $7.7 \%$ of stuttering children had anxiety ${ }^{[2]}$. Decrease incidence of anxiety and withdrawal symptoms among children group. This is explained by that children who stutter haven't been aware of their conditions, so no need for fear and withdrawal symptoms ${ }^{[36]}$. It was claimed that anxiety in stuttering people might increase over time until exceeding normal limits in adolescents and adults.

The present study's somatic complaints were $57.1 \%$ in adolescents, $23.5 \%$ in preadolescents, while children didn't suffer from somatic complaints due to lack of awareness. GiorgettiMde et al., report that (3.1\%) with no statistical difference between the stuttering and non-stuttering studied groups, suggesting that children did not make any effort to control their stuttering; thus, either fatigue or somatic symptoms were not noticed by their parents ${ }^{[14]}$. That's came in contrary to Craig et al., where the studied group was adult stutterers who reported that the trials to adjust stuttering could cause physical and emotional fatigue ${ }^{[37]}$.

\section{As regards externalizing problems:}

- $\quad$ Aggressive behavior was more manifested in preadolescents and adolescents $(41.2 \%$ and $42.9 \%$, respectively), while in children, they were least displayed $(6.3 \%)$, while in the Portuguese study, it was $12.5 \%$ in the studied group ${ }^{[14]}$.

- Rule-breaking behavior presented (41.2\% of preadolescents, $7.1 \%$ of adolescents), while this behavior wasn't in all children of the current study. In contrary, it was $3.1 \%$ in the Portuguese study in all the studied groups ${ }^{[14]}$. Regarding externalizing symptoms, parents of the stutterers noticed comorbid aggressive behavior is more common than rule-breaking behavior. 
- Social problems scores in the social field or difficulties in social interactions ${ }^{[25,38]}$ were clinical scores in the present study $(57.1 \%$ in adolescents, $58.8 \%$ in preadolescents, and $6.3 \%$ in children). It was clinical in $9.4 \%$ of Portuguese studies and $34.4 \%$. was subclinical. Stuttering can cause impaired social interactions ${ }^{[38,39,40]}$. Features related to social affection in stutterers were described as escape behavior or fear and avoidance of social interactions ${ }^{[12]}$. Social problems were more prevalent than both thought and attention problems. Therefore, aggressive and social problems may be considered essential changes in stutterers.

These problems become more complex in adolescence, including anxiety, social communication, and educational difficulties ${ }^{[41]}$.

In the current study attention problems were presented in preadolescents and adolescents (29.4\% and $28.6 \%$, respectively). This study also showed a positive correlation, but it did not reach a significant value. That meant that attention problems and stuttering have no etiological relationship, but the existence of one disorder may influence the other, while in children, they were the least manifested $(6.3 \%)$. While in the Portuguese study, it was $3.1 \%$ in the studied group..$^{[14]}$

Lastly, as regards thought problems, preadolescents were the more affected group (35.3\%), in adolescents $7.1 \%$ only was affected while all the children were spared. While in the Portuguese study, it was $6.2 \%$ in the studied group ${ }^{[14]}$.

In comparing the stuttering and non- stuttering groups regarding all scores of $\mathrm{CBCL}$, there was a statistically significant difference as $90.6 \%$ of the stuttering group showed clinical scores as regards all scores while this percentage was 53.1 in the nonstuttering group ${ }^{[14]}$.

The high prevalence of all comorbid psychiatric symptoms in stutterers in the current study compared with the foreign studies may be explained by the lack of cognitive behavior therapy in Egypt in the ordinary management program of stuttering, including speech assessment and intervention.

In present study, as regards the timing of psychiatric symptoms associated with stuttering, anxious/ depressed symptoms increased with the age of the stutterers to be most manifested in preadolescents $(88.2 \%)$, adolescents $(85.7 \%)$, and least displayed in children $(12.5 \%)$

Among the children group: $62.5 \%$ of stutterers were moderate in severity. As the severity increased, there were variant symptoms that may be accomplished with them, except somatic complaints. It needed more experience and suffering to internalize the secondary reaction towards stuttering. Among the preadolescent group, $41.2 \%$ were very severe cases of stuttering, which explains that. There weren't correlations between SSI and symptoms except for rule- breaking habits, aggressive behavior, which may explained by emotional disturbances for puberty changes. There were no correlations among adolescents' stutterers as $57.1 \%$ were very severe with no specific symptoms for them as they passed along all ages and all signs.

There were highly significant correlations between stuttering severity and all psychological symptoms except attention problems, rule-breaking habits, and somatic complaints among all age groups. As explained that, there was no direct correlation between severity and these symptoms. Still, they related to the community they lived in a defense mechanism from stuttering and linked to changes in stuttering frequency ${ }^{[42]}$.

In summary, these findings contributed to classifying stutterers' behavior and social competency and would point to a better understanding of the impact of stuttering on their social life.

\section{CONCLUSION}

Understanding of behavior and social competency of stutterers may help the management understand the multidimensionality of stuttering, and behavior therapy (CBT) is mandatory for those stutterers alongside with the ordinary management program, including speech assessment and intervention. On the other hand, CBT should be used as prevention in stutterers without comorbid psychiatric symptoms.

\section{LIST OF ABBREVIATIONS}

Arabic Stuttering Severity Instrument (A- SSI)

Auditory Perceptual Assessment (APA)

Child Behavior Checklist $\quad$ (CBCL)

Cognitive behavior therapy $\quad$ (CBT)

Intelligence Quotient

Stuttering Severity Instrument

\section{CONFLICT OF INTEREST}

There are no conflicts of interest.

\section{REFERENCES}

1. Guitar, B. (2013). Stuttering: An integrated approach to its nature and treatment $\left(4^{\text {th }}\right.$ ed). Baltimore, MD: Lippincott Williams \& Wilkins 
2. Baz H and Elsayed H (2010): Preschool Stuttering Children with Comorbid Psychiatric Disorders, EJENTAS Egyptian Journal of ear, nose, throat and Allied Sciences Volume 11, June 2010

3. Sikandar Mz, Tahir Fn, Shah Sia. Self-Esteem and Anxiety among Young Adult Male Stutterers of Central PunjabBiomedica Jan-Mar 2019; 35(1):37-40

4. Craig, A., Hancock, K., Tran, Y., Craig, M., \& Peters, $\mathrm{K}$. Epidemiology of stuttering in the community across the entire life span. Journal of speech, language, and hearing research : JSLHR, 45(6), 1097-1105. https:// doi.org/10.1044/1092-4388(2002/088)

5. De Nil LF, Brutten GJ. Speech-associated attitudes of stuttering and nonstuttering children [published correction appears in J Speech Hear Res 1991 Jun;34(3):703]. J Speech Hear Res. 1991;34(1):60-66. doi:10.1044/jshr.3401.60

6. Martine Vanryckeghem, Carl Hylebos, Gene J Brutten, Martin Peleman, The relationship between communication attitude and emotion of children who stutter, Journal of Fluency Disorders, Volume 26, Issue 1, 2001, Pages 1-15, ISSN 0094-730X, https://doi.org/10.1016/S0094-730X(00)00090-5. (https://www.sciencedirect.com/science/article/pii/ S0094730X00000905)

7. Bleek B, Reuter M, Yaruss JS, Cook S, Faber J, Montag C. Relationships between personality characteristics of people who stutter and the impact of stuttering on everyday life. J Fluency Disord. 2012;37(4):325-333. doi:10.1016/j.jfludis.2012.07.003

8. Raghavendra P, Bornman J, Granlund M, BjörckAkesson E. The World Health Organization's International Classification of Functioning, Disability and Health: implications for clinical and research practice in the field of augmentative and alternative communication. Augment Altern Commun. 2007;23(4):349-361. doi:10.1080/07434610701535905

9. Briley PM, Ellis C. Behavioral, social, and emotional well-being in children who stutter: the influence of race-ethnicity [published online ahead of print, 2020 Aug 5]. LogopedPhoniatrVocol. 2020;1-9. doi:10.108 0/14015439.2020.1801833

10. Craig, Ashley. (2000). The Developmental Nature and Effective Treatment of Stuttering in Children and Adolescents. Journal of Developmental and Physical Disabilities. 12. 173-186. 10.1023/A:1009463703647
11. Johannes Von Tiling, Listener perceptions of stuttering, prolonged speech, and verbal avoidance behaviors, Journal of Communication Disorders, Volume 44, Issue 2, 2011, Pages 161-172, ISSN 00219924, https://doi.org/10.1016/j.jcomdis.2010.09.002. (https://www.sciencedirect.com/science/article/pii/ S0021992410000791)

12. MacKinnon SP, Hall S, Macintyre PD. Origins of the stuttering stereotype: stereotype formation through anchoring-adjustment. J Fluency Disord. 2007;32(4):297-309. doi:10.1016/j. jfludis.2007.03.003

13. Hollister, Julia Elizabeth. "Effortful control and adaptive functioning in school-age children who stutter." PhD (Doctor of Philosophy) thesis, University of Iowa, 2015. https://doi.org/10.17077/etd.1z9h6ynb

14. GiorgettiMde P, Oliveira CM, Giacheti CM Behavioral and social competency profiles of stutterers. Codas. 2015;27(1):44-50. doi:10.1590/2317$1782 / 20152013065$

15. Smith KA, Iverach L, O'Brian S, Kefalianos E, Reilly S. Anxiety of children and adolescents who stutter: a review. J Fluency Disord. 2014;40:22-34. doi:10.1016/j.jfludis.2014.01.003

16. Bloodstein, O., \& Ratner, N. B. A handbook on stuttering. Published in 2008 in Clifton Park NY) by Thomson/Delmar Learning.

17. Iverach L, Jones M, McLellan LF, et al. Prevalence of anxiety disorders among children who stutter J Fluency Disord. 2016;49:13-28. doi:10.1016/j. jfludis.2016.07.002.

18. Ambrose, Nicoline. (2004). Theoretical Perspectives on the Cause of Stuttering. CICSD. 31. 80-91. 10.1044/cicsd 31 S 80.

19. Rifaie N. Arabicizing and standardizing the Stuttering Severity Instrument (SSI) on the Arabic environment. Ain Shams Med J 1999; 50:7-9: 907-914.

20. Riley GD. A stuttering severity instrument for children and adults. J Speech Hear Disord. 1972; 37(3):314-322. doi:10.1044/jshd.3703.314

21. Riley GD. Stuttering severity instrument for children and adults (SSI-3) 3rd ed. Pro Ed; Austin: TX: 1994.

22. Elsheikh MM. Psychiatric morbidity in first-degree relatives of a sample of ADHD children. 2003, MD dissertation in psychiatry, Ain Shams University, Neuropsychiatric Department. 
23. Thomas M Achenbach; Leslie Rescorla Manual for the ASEBA school-age forms \& profiles : an integrated system of multi-informant assessment. Publisher: Burlington, VT: ASEBA, [2001] C2001

24. Iverach, L., Jones, M., O'Brian, S., Block, S., Lincoln, M., Harrison, E., Hewat, S., Cream, A., Menzies, R. G., Packman, A., \& Onslow, M. The relationship between mental health disorders and treatment outcomes among adults who stutter. Journal of fluency disorders, 34(1), 29-43. https://doi.org/10.1016/j. jfludis.2009.02.002

25. Yaruss JS.Assessing quality oflifein stuttering treatment outcomes research. J Fluency Disord. 2010;35(3):190202. doi:10.1016/j.jfludis.2010.05.010

26. Bricker-Katz G, Lincoln M, McCabe P. A lifetime of stuttering: how emotional reactions to stuttering impact activities and participation in older people. DisabilRehabil. 2009;31(21):1742-1752. doi:10.1080/09638280902738672

27. O'Brian S, Jones M, Packman A, Menzies R, Onslow M. Stuttering severity and educational attainment. J Fluency Disord. 2011;36(2):86-92. doi:10.1016/j. jfludis.2011.02.006

28. Langevin M, Packman A, Onslow M. Peer responses to stuttering in the preschool setting. Am J Speech Lang Pathol. 2009;18(3):264-276. doi:10.1044/10580360(2009/07-0087)

29. Gunn A, Menzies RG, Onslow M, et al. Phase I trial of a standalone internet social anxiety treatment for adolescents who stutter: iBroadway. Int J Lang CommunDisord. 2019;54(6):927-939. doi:10.1111/1460-6984.12496

30. Snyder, Gregory. (2001). Exploratory research in the measurement and modification of attitudes toward stuttering. Journal of Fluency Disorders. 26. 149-160. 10.1016/S0094-730X(01)00092-4.

31. Craig A, Hancock K, Tran Y, Craig M. Anxiety levels in people who stutter: a randomized population study. Journal of Speech, Language, and Hearing Research : JSLHR. 2003 Oct;46(5):1197-1206. DOI: 10.1044/1092-4388(2003/093).

32. Yaruss JS, Quesal RW, Reeves L, et al. Speech treatment and support group experiences of people who participate in the National Stuttering Association. J Fluency Disord. 2002;27(2):115-134. doi:10.1016/ s0094-730x(02)00114-6
33. Andrade CR, Sassi FC, Juste FS, Ercolin B. Quality of life of individuals with persistent developmental stuttering. Pro Fono. 2008;20(4):219-224. doi:10.1590/ s0104-56872008000400003

34. Tran Y, Blumgart E, Craig A. Subjective distress associated with chronic stuttering. J Fluency Disord. 2011;36(1):17-26. doi:10.1016/j.jfludis.2010.12.003

35. Abdelhamid, Ahmed \&Mesallam, Tamer \&Shoeib, Rasha\&Kaddah, Fatma. Article Title: Anxiety profile in children and adolescents with stuttering. Egyptian Journal of Ear, Nose, Throat and Allied Sciences. 21. 10.21608/EJENTAS.2019.11729.1098.

36. Smith KA, Iverach L, O'Brian S, Kefalianos E, Reilly S. Anxiety of children and adolescents who stutter: a review. J Fluency Disord. 2014;40:22-34. doi:10.1016/j.jfludis.2014.01.003

37. Craig A, Blumgart E, Tran Y. The impact of stuttering on the quality of life in adults who stutter. J Fluency Disord. 2009;34(2):61-71. doi:10.1016/j. jfludis.2009.05.002

38. Craig A. The association between quality of life and stuttering. J Fluency Disord. 2010;35(3):159-160. doi:10.1016/j.jfludis.2010.08.002

39. Van Borsel J, Brepoels M, De Coene J. Stuttering, attractiveness and romantic relationships: the perception of adolescents and young adults. J Fluency Disord. 2011;36(1):41-50. doi:10.1016/j. jfludis.2011.01.002

40. Beilby JM, Byrnes ML, Meagher EL, Yaruss JS. The impact of stuttering on adults who stutter and their partners. J Fluency Disord. 2013;38(1):14-29. doi:10.1016/j.jfludis.2012.12.001

41. Scheurich JA, Beidel DC, Vanryckeghem M. Exposure therapy for social anxiety disorder in people who stutter: An exploratory multiple baseline design. J Fluency Disord. 2019; 59:21-32. doi:10.1016/j. jfludis.2018.12.001

42. Conture EG, Kelly EM, Walden TA. Temperament, speech and language: an overview. J Commun Disord. 2013; 46(2):125-142. doi:10.1016/j. jcomdis.2012.11.002 